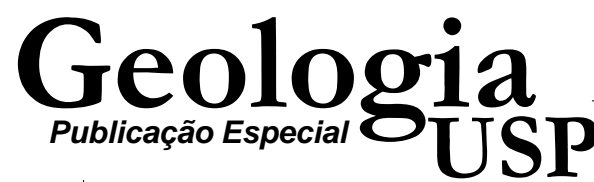

\section{O Trabalho de Formatura: Forma ou Conteúdo?}

\author{
Gergely Andres Julio Szabó (gajszabo@usp.br), Gianna Maria Garda, lan McReath \\ Departamento de Mineralogia e Geotectônica - Instituto de Geociências - USP \\ R. do Lago 562, CEP 05508-080, São Paulo, SP, BRA
}

Recebido em 12 de dezembro de 2006; aceito em 29 de janeiro de 2007

Palavras-chave: curso de Geologia, estrutura curricular, trabalho de Graduação.

\section{RESUMO}

Este trabalho faz uma avaliação da disciplina 0440500 - Trabalho de Formatura, do curso de Geologia do Instituto de Geociências da USP, desde a sua implantação, em 1998, até 2006, período esse no qual mais de 300 alunos se matricularam nela. Trata-se de uma disciplina introduzida quando da reforma da estrutura curricular do curso em 1993, e que tem por objetivo oferecer aos alunos formandos a oportunidade de desenvolverem projetos individuais, de duração anual, orientados por docentes da USP de sua escolha e avaliados por uma Comissão responsável pela disciplina, com a ajuda de Relatores. Além da avaliação da disciplina, o trabalho traz contribuições para uma eventual revisão da sua estrutura.

Keywords: undergraduate course in Geology, plan of study, honors research thesis.

\begin{abstract}
This paper discusses the evaluation of the course entitled "Graduation Project", taken by undergraduate students of Geology at the Instituto de Geociências, São Paulo University (USP) in their last year. The course is mandatory, and consists of a year-long individual Project, on subjects chosen by the students, under the guidance of professors from the University, supervised by a Committee of professors with the help of reviewers specialized in the subjects of the various Projects. This course was first offered in 1998, in the wake of the reform of the Geology course started in 1993, and has since been taken by more than 300 students. Apart from the evaluation, suggestions are given for the improvement of the course in the future.
\end{abstract}




\section{INTRODUÇÃO}

Desde sua implantação no currículo do curso de Geologia do Instituto de Geociências da USP, o número de alunos matriculados na disciplina 0440500 - Trabalho de Formatura cresceu de 17, em 1998, para 58, em 2006. Acompanha cada aluno um orientador (docente da USP, que formalmente pode orientar, no máximo, dois alunos); eventualmente, um co-orientador (docente ou não-docente); um relator (docente ou não-docente) e um membro da Comissão do Trabalho de Formatura (CTF - docente do IGc-USP). Cada membro da CTF tem acompanhado, em média, cinco a sete trabalhos. Cabe à CTF a atribuição de notas e freqüência.

Este ano, compõem a CTF 12 membros; o total de orientadores docentes é 40 e de co-orientadores, 22 (docentes e não-docentes). Ao todo, são 43 docentes envolvidos no TF-2006, o que representa $70 \%$ de todo o corpo docente do Instituto de Geociências.

O Trabalho de Formatura (TF) é uma disciplina obrigatória, anual, com quatro créditos-aula e 22 créditos-trabalho; totaliza 720 horas, o que equivale a 12 disciplinas de quatro créditos-aula. O aluno é avaliado pelo Projeto Inicial, Relatório de Progresso, Monografia, apresentação pública, resumo ou pôster e defesa do Trabalho de Formatura, perante uma banca de avaliação presidida pelo membro da CTF e composta pelo orientador e relator.

\section{RETROSPECTIVA}

O Trabalho de Formatura foi uma das grandes inovações da Estrutura Curricular do curso de Geologia da USP aprovada em 1993 e implantada a partir de 1994. O primeiro Regulamento do Trabalho de Formatura (TF) foi aprovado pela Congregação em 26 de setembro de 1997, e a primeira turma, de 18 alunos, cursou a nova disciplina em 1998. Desde então, 9 turmas, totalizando 302 alunos, cursaram a disciplina, incluindo neste número os 58 alunos que estão nela matriculados em 2006. O número de alunos variou da seguinte maneira ao longo dos anos (Tabela 1):

Tabela 1. Número de alunos matriculados na disciplina Trabalho de Formatura por ano.

\begin{tabular}{lccccccccc}
\hline Ano & 1998 & 1999 & 2000 & 2001 & 2002 & 2003 & 2004 & 2005 & 2006 \\
Alunos & 18 & 17 & 24 & 36 & 36 & 52 & 28 & 33 & 58 \\
\hline
\end{tabular}

O Regulamento do TF sofreu várias alterações ao longo desse período. Estas alterações incluíram: a incorporação da figura do Relator no acompanhamento dos TFs e na banca final de avaliação, figura essa informalmente introduzida pela primeira Comissão; mudanças nos critérios de escolha do Orientador, que passou a ser potencialmente qualquer docente da USP, não apenas do IGc; e mudanças na constituição da CTF, que foi sendo ampliada, em função do aumento do número de matrículas na disciplina. Aúltima modificação do Regulamento, válida a partir de 2007, inclui mudança nos requisitos, que passam da limitação da carga horária necessária para o aluno completar o curso para a adoção de três disciplinas-requisito anuais do quarto ano (Mapeamento Geológico, Geologia Histórica e do Brasil e Prospecção e Pesquisa Mineral). Também alterou os critérios de avaliação, dando peso maior à Monografia ou Relatório Final, e a constituição da CTF, que passa a ser constituída com base na relação "ideal” de um membro para cada 5 alunos matriculados.

Os objetivos da disciplina Trabalho de Formatura, quando da sua implantação, foram os seguintes:

1. permitir ao aluno uma finalização mais independente de sua formação superior, através do desenvolvimento de um projeto individual, de própria escolha;

2. oferecer ao aluno formando treinamento no planejamento e execução de um projeto profissional (ou acadêmico) e na sistematização, tratamento, interpretação dos dados e apresentação dos resultados;

3. permitir uma eventual e optativa "especialização precoce", combinando o desenvolvimento do TF em uma determinada área com a escolha de um conjunto de disciplinas eletivas (optativas) tematicamente coerente.

Os itens 1 e 2 de fato vêm sendo observados: pela carga didática da disciplina Trabalho de Formatura, os alunos dedicam praticamente um ano inteiro ao seu projeto individual e, pelos comentários de ex-alunos que realizaram TF, a experiência permitiu-lhes aprender a organizar e executar projetos e a apresentar os resultados de maneira mais eficiente. Já o terceiro objetivo, este foi criado como uma "solução de compromisso" na discussão que encerrou a implantação da nova Estrutura Curricular, onde se contrapôs o modelo de um profissional Geólogo de formação ampla e generalista com o de um profissional especializado em determinada área (Hidrogeologia, Geologia Ambiental, Mineração, Geologia de Engenharia etc.), já a partir da sua formação universitária básica. Com a definição pelo modelo do profissional de ampla formação, optou-se por uma "especialização precoce optativa”, através de "Áreas de Concentração", onde o desenvolvimento do TF em determinada área temática, combinado com a escolha de disciplinas optativas de um rol tematicamente coerente, permitiria ao aluno obter um certificado de "Especialização” em uma determinada Área de Concentração. Este modelo acabou gerando uma proliferação de disciplinas optativas as mais diversas, muitas das quais com baixa procura e, na prática, não vingou, uma vez que pou- 
quíssimos alunos se valeram, desde que o Trabalho de Formatura foi criado, desta opção de especialização precoce. Na falta de uma avaliação regular, como discutido abaixo, fica difícil estimar quantos alunos se colocaram no mercado de trabalho em área temática afim daquela em que desenvolveram seu projeto de TF.

Em termos de distribuição dos TFs por áreas temáticas dentro das Geociências, a situação está resumida na Tabela 2, ano a ano e totalizada até 2006. Vale mencionar que a atribuição dos TFs individuais às áreas temáticas, tais como apresentadas, pode ser motivo de discussão, em vários casos. Em Hidrogeologia, por exemplo, estão incluídos trabalhos que utilizaram métodos de Geofísica ou de Geoquímica na sua execução, assim como vários trabalhos incorporados à área de Geologia Econômica e Recursos Minerais baseiam-se fortemente em tópicos de Mineralogia Aplicada. Em cada caso, tentou-se avaliar qual era a ênfase principal do trabalho: se a elucidação de um problema utilizando determinadas ferramentas, ou se a aplicação ou desenvolvimento de uma determinada ferramenta em especial.

A avaliação da eficiência da disciplina Trabalho de Formatura como ferramenta didática na formação dos profissionais graduados pelo IGc-USP tropeça na falta de um "feedback” eficiente e sistemático por parte dos formandos nos últimos anos: seria necessário desenvolver o hábito de manter contato com os graduados, através de um banco de endereços atualizado regularmente, e recorrer a eles, através de questionários periódicos, para avaliar a eficácia não só do Trabalho de Formatura, como do conjunto de disciplinas do curso de Geologia como um todo, nas suas atividades profissionais.

Com relação aos TFs até hoje realizados no curso de Geologia do IGc-USP, percebe-se as seguintes situações: a. situação "ideal”: TF como continuação ou em combinação com Projeto IC (FAPESP, PIBIC - vertente "acadêmica”) e TF em combinação com estágio externo (vertente "profissionalizante");

b. “menos ideal”: projeto TF desvinculado de Projeto IC ou estágio em paralelo;

c. "não ideal”: idem b, mas com franco favorecimento das atividades de estágio ou IC em detrimento do TF.

\section{DEFEITOS E VIRTUDES DO ATUAL MODELO DE TRABALHO DE FORMATURA}

Parte dos defeitos observados no atual modelo de Trabalho de Formatura adotado no curso de Geologia do IGcUSP decorre de suas virtudes. Assim, o esquema detalhadamente organizado que vigora é muito exigente em termos da disponibilidade do corpo docente, tanto como membros da CTF como Orientadores e Relatores. Por conta da distribuição desigual, vários docentes acabam se envolvendo com maior intensidade, orientando dois TFs e acompanhando até cinco ou seis adicionais como membros da CTF, ou como Relatores. Como mencionado antes, parte significativa (70\%) do corpo docente do IGc encontra-se envolvida na disciplina este ano (2006). Outro problema de difícil solução é a heterogeneidade nos critérios de avaliação dos Projetos Iniciais, Relatórios e Monografias. À dificuldade de avaliar, em um só pacote, trabalhos de áreas temáticas as mais variadas soma-se a variedade de “estilos” dos Relatores: alguns são detalhistas, perfeccionistas e "severos", enquanto outros fazem uma análise mais superficial dos trabalhos avaliados. Neste caso, sobressai a importância da CTF como fórum "moderador” das avaliações individuais, procurando minimizar esta heterogeneidade.

Tabela 2. Distribuição dos Trabalhos de Formatura apresentados pelo curso de Geologia do IGc-USP por áreas temáticas, ano a ano.

\begin{tabular}{|c|c|c|c|c|c|c|c|c|c|c|}
\hline Áreas & 1998 & 1999 & 2000 & 2001 & 2002 & 2003 & 2004 & 2005 & 2006 & Total \\
\hline Mineralogia e Petrologia (acadêmica) & 2 & 3 & 1 & 3 & 0 & 6 & 4 & 4 & 10 & 33 \\
\hline Mineralogia e Petrologia (aplicada) & 4 & 2 & 3 & 4 & 6 & 5 & 2 & 1 & 5 & 32 \\
\hline Estratigrafia, Sedimentologia e Paleontologia & 3 & 5 & 6 & 7 & 5 & 8 & 1 & 6 & 17 & 58 \\
\hline Geol.Regional, Mapeamento, Geol.Estrutural & 0 & 0 & 2 & 5 & 2 & 5 & 6 & 5 & 6 & 31 \\
\hline Geol.Econômica, Recursos Minerais, Prospecção & 2 & 0 & 2 & 0 & 0 & 0 & 5 & 5 & 1 & 15 \\
\hline Geotecnologias, Sensoreamento Remoto & 2 & 1 & 1 & 0 & 0 & 0 & 0 & 0 & 2 & 6 \\
\hline Geoquímica, Geologia Isotópica & 1 & 0 & 1 & 2 & 0 & 2 & 2 & 3 & 2 & 13 \\
\hline Geol.Engenharia, Geotecnia, Riscos Geológicos & 3 & 3 & 2 & 6 & 4 & 5 & 0 & 3 & 4 & 30 \\
\hline Hidrogeologia, Geologia Ambiental & 1 & 3 & 5 & 7 & 14 & 17 & 4 & 4 & 8 & 63 \\
\hline Geofísica, Matemática Aplicada à Geologia & 0 & 0 & 1 & 0 & 3 & 4 & 3 & 2 & 2 & 15 \\
\hline Geologia e Educação, Divulgação das Geociências & 0 & 0 & 0 & 2 & 1 & 0 & 1 & 0 & 0 & 4 \\
\hline Miscelânea & 0 & 0 & 0 & 0 & 1 & 0 & 0 & 0 & 1 & 2 \\
\hline Total & 18 & 17 & 24 & 36 & 36 & 52 & 28 & 33 & 58 & 302 \\
\hline
\end{tabular}


Outro defeito a ser considerado é a dimensão da disciplina Trabalho de Formatura no contexto da atual Estrutura Curricular e das diretrizes curriculares em estudo para os cursos de Geologia (Nummer et al., 2005). O TF domina amplamente o $5^{\circ}$ ano do curso de Geologia do IGc-USP, exigindo que a formação do aluno esteja praticamente completa ao final do $4^{\circ}$ ano. Se, por um lado, isto é salutar por oferecer ao aluno um espaço maior para opções individuais na sua formação universitária, por outro acaba "espremendo" as disciplinas tradicionais ou presenciais, causando uma sobrecarga atualmente bastante sentida no $3^{\circ}$ e $4^{\circ}$ ano do curso. Adicionalmente, o conteúdo temático da disciplina, por ser fundamentalmente de escolha individual do aluno, não se soma ao rol de tópicos que definem as atribuições profissionais dos formados pelo curso.

Por fim, o próprio caráter pouco convencional da disciplina causa alguns problemas na sua administração e controle no Sistema Júpiter: controle de freqüência, atribuição de carga didática aos docentes envolvidos (membros da CTF e Orientadores) etc.

\section{O QUE HÁ NO JUPITERWEB SOBRE TRABALHOS DE FORMATURA EM OUTRAS UNIDADES}

A Tabela 3 apresenta o resultado da busca no Jupiterweb das disciplinas que, de maneira semelhante ao Trabalho de Formatura do IGc-USP, configuram atividade de conclusão de curso. As palavras-chave utilizadas na pesquisa foram: "Formatura”, “Trabalho Graduação”, "Trabalho Conclusão” e "Trabalho Final”.

Essas disciplinas podem ser semestrais, quadrimestrais e anuais. As 62 disciplinas denominadas "Projeto" ou "Trabalho de Formatura” (P/TF) estão assim distribuídas pelos campi da USP: em São Paulo, Instituto de Geociências, Escola Politécnica (exceto Mecatrônica), Matemática e Escola de Artes e Ciências Humanas (USP Leste); em São Carlos, Computação e Estatística; em Ribeirão Preto, Física, Matemática e Contabilidade. São semestrais $70 \%$ das 62 disciplinas, com número de créditos muito variado, divido ou não em créditos-aula (de 0 a 6) e créditos-trabalho (de 0 a 19) - 47\% das disciplinas semestrais adotam 4 créditos-aula e 0 créditos-trabalho.

Tabela 3. Disciplinas de conclusão de curso, segundo o JupiterWeb.

\begin{tabular}{lc}
\hline \multicolumn{1}{c}{ Designação da disciplina } & $\begin{array}{c}\text { Número de } \\
\text { disciplinas }\end{array}$ \\
\hline Projeto de Formatura & 30 \\
Projeto de Graduação & 16 \\
Projeto ou Trabalho de Conclusão de Curso & 54 \\
Trabalho de Formatura & 32 \\
Trabalho de Graduação & 23 \\
Trabalho Final & 4 \\
\hline
\end{tabular}

O desenvolvimento do P/TF pode ser individual ou em grupos de dois a oito alunos. No primeiro módulo, o aluno elabora o projeto de formatura e, muitas vezes, participa de disciplinas correlatas ao projeto. No módulo seguinte, o projeto é implantado ou simulado. A avaliação é realizada pelo docente responsável pela disciplina, pelo docente orientador, por equipes de três ou quatro docentes ou por bancas compostas por três docentes.

As 54 disciplinas denominadas Trabalho de Conclusão de Curso (TCC) estão distribuídas pelos campi da USP de Ribeirão Preto (Física, Matemática e Faculdade de Filosofia, Ciências e Letras), Bauru, São Carlos, Piracicaba (Agronomia) e São Paulo (Escola de Artes e Ciências Humanas, Escola Politécnica - Mecatrônica, Escola de Comunicações e Artes, Faculdade de Economia e Administração, Faculdade de Educação e Escola de Medicina). Mais de 90\% dessas disciplinas são semestrais, com número de créditos-aula variando de 0 a 6 e de créditos-trabalho de 0 a 12. Em geral, um docente é responsável pela disciplina.

São considerados TCCs: Iniciação Científica, Trabalho Científico, Relatório Final (integrando, pelo menos, duas disciplinas da graduação) e Monografia. A avaliação no primeiro módulo é, em geral, a “convencional”, ou seja, provas e seminários. A defesa do TCC se dá perante banca de dois docentes e, em alguns casos, com apresentação pública.

As principais dúvidas que não se esclareceram com a pesquisa do JupiterWeb, foram em relação a disciplinas prérequisito, número de créditos mínimo para a realização do P/TF ou TCC e como se configura o "potencial formando". Quando o P/TF ou TCC são compostos por dois módulos, com avaliações específicas para cada módulo, não fica claro se o módulo II deve necessariamente ser realizado no período seguinte à obtenção de aproveitamento e créditos no módulo I e nas disciplinas correlatas. Quando o P/TF ou TCC contempla estágio supervisionado, também não se tem informações sobre o controle de freqüência e como se dá a avaliação.

Nem sempre há a informação sobre a recuperação na disciplina, mas, grosso modo, não há.

\section{CONCLUSÕES}

Avaliando o histórico da disciplina Trabalho de Formatura até hoje no IGc-USP e considerando as atribuições profissionais dos geólogos perante o CREA, sugerimos a criação de um grupo de trabalho que estude a possibilidade de remodelar a disciplina, considerando os seguintes aspectos:

1. redução da carga horária, permitindo maior flexibilidade e volume de disciplinas eletivas;

2. "semestralização" do TF, com subdivisão em duas disciplinas (por exemplo, "Projeto” e “TF”), oferecidas continuamente nos dois semestres; 
3. otimização do envolvimento do corpo docente e da infra-estrutura do Instituto;

4. considerar a opção por um TF vinculado a um conjunto coerente de disciplinas.

O importante seria manter o padrão de qualidade que caracteriza a disciplina desde sua implantação, mas otimizando o tempo dispendido pelos alunos e docentes.

\section{REFERÊNCIAS BIBLIOGRÁFICAS}

NUMMER, A. R.; GODOY, A. M.; LAZZAROTTO, A.; CARNEIRO, C. D. R.; SCHULTZ, C. L.; TUBBS FILHO, D.; GUIMARÃES, E. M.; ALTHOFF, F.; ASSIS, J. F. P.; PINHO, F. E. C.; SOBREIRA, F.; CARVALHO, I. S.; SABADIA, J.A.B.; FERNANDES FILHO, L. A.; TOLEDO, M. C. M. de; FERNANDES, M. L. S.; COSTA, R. D. da; MACHADO, R.; MENEGAT, R.; NADALIN, R. J.; SANTOS, R. A. A. dos; VASCONCELOS, S. M. S.; MARQUES, T. M.; SOUZA, Z. S. de. Diretrizes curriculares para os cursos de graduação em Geologia e Engenharia Geológica. Terrae Didatica, v. 1, n. 1, p. 64-69, 2005. Disponível em: <http://www.ige. unicamp.br/terraedidatica/v1n1/t_didatica_2005_ v01n01_p064-069_nummer_et_al.pdf>. Acesso em: 04 out. 2006. 